\title{
Jaundice associated with naproxen
}

\author{
R. M. M. VICTORINO* \\ M.D. \\ J. C. B. Silveira \\ M.D. \\ A. BAPTISTA \\ M.D. \\ M. C. DE MOURA \\ M.D.
}

University Hospital of Santa Maria, Department of Medicine II (Patologia Medica) Lisbon, Portugal

\begin{abstract}
Summary
Hepatic injury in association with naproxen therapy is described and documented by liver biopsy in one patient. Histological findings were consistent with a drug-induced hepatitis, and cessation of therapy led to reversal of the clinical and biochemical changes. Circumstantial evidence is in favour of a hypersensitivity response to the drug rather than direct hepatotoxicity. Increased awareness of clinicians of this probably rare side effect of naproxen may help prompt identification of similar cases.
\end{abstract}

\section{Introduction}

Naproxen ( $(+)-6$ methoxy 2-naphthaleneacetic acid), a non steroidal anti-inflammatory agent, is currently widely used in rheumatic conditions. Slight and transient changes in serum transaminase levels, regressing despite continued therapy, have been reported by Frenger and Norbach (1973) and more recently jaundice was suggested as a possible side effect of naproxen (Bass, 1974; Law and Knight, 1976). These 2 case reports were not histologically documented. The authors now present what, to their knowledge, is the first histologically documented case of jaundice associated with naproxen.

\section{Case report}

A 66-year-old Angolan black male presented with a 2-year history of mild back pain and a diagnosis of spinal ostheoarthrosis. No treatment was given until January 1977 when he was started on naproxen $250 \mathrm{mg}$ twice/day and Neurobion (vitamin $\mathbf{B}_{1}, \mathbf{B}_{6}$ and $B_{12}$ ) injections twice/week. One month after commencing this treatment he developed fever for 4 days with malaise and this was followed by appearance of dark urine and marked jaundice. He had

* Present address for correspondence: Dr Rui M. M. Victorino, Royal Postgraduate Medical School, MRC Building 5th floor Gastro-Intestinal Unit, Du Cane Road, London W12 OHS. no complaints of abdominal pain, pruritus or rasiej no history of contact with cases of viral hepatitis ang no alcohol consumption preceding the episoder Excluding the vitamin preparation during the pres ceding month, he had had no injections or transo fusions in the 2 previous years. After the appearance of jaundice, naproxen was stopped and 10 days later he was admitted to hospital for investigation.

Physical examination at this time revealed marked jaundice, a slightly tender liver palpable $5 \mathrm{~cm}$ beto the costal margin and no other positive findings.

Laboratory tests showed a normal $\mathrm{Hb}$, blood fing haematocrit, blood urea nitrogen, glucose, electio lytes and prothrombin time. Erythrocyte sedp mentation rate was $15 \mathrm{~mm}$ in $1 \mathrm{st} \mathrm{hr}$ (Westergren Serum aspartate transferase, 102 u. (normal range 5-40 u.). Total bilirubin, $99 \cdot 2 \mu \mathrm{mol} / \mathrm{l}$. Alkalin phosphatase, 19 Bodansky u. (normal range 1.5-5.0 u.). Cholesterol, $5.98 \mathrm{mmol} / \mathrm{l}$. $\mathrm{HB}_{\mathrm{s}}$ antigen and anti-nuclear, antimitochondrial and ant smooth muscle antibodies were all negative.

Percutaneous liver biopsy was then performe The histological appearances revealed preservation. of normal architecture. The most prominent ab. normal feature was the accumulation of PASS positive pigment in clumped Kuppfer cells and portal tract phagocytes providing evidence of previous liver cell death (Fig. 1). A mild degree of steatosis with small and medium sized vacuoles (Fig. 2) and rare and small foci of mononuclear cett infiltration, scattered through the parenchyma were present. Portal tracts were sharply limited and moderately enlarged with oedema and infiltration be mononuclear cells and some eosinophils (Fig. 3) The changes were interpreted as those of a resolving acute hepatitis-type lesion. In 2 weeks the hepato megaly disappeared and the patient was dischargee with a mild residual jaundice and almost complete regression to normal of liver function tests: serun aspartate transferase, $17 \mathrm{u}$., total bilirubin, $37 \cdot 6 \mu \mathrm{mol}$ 西 


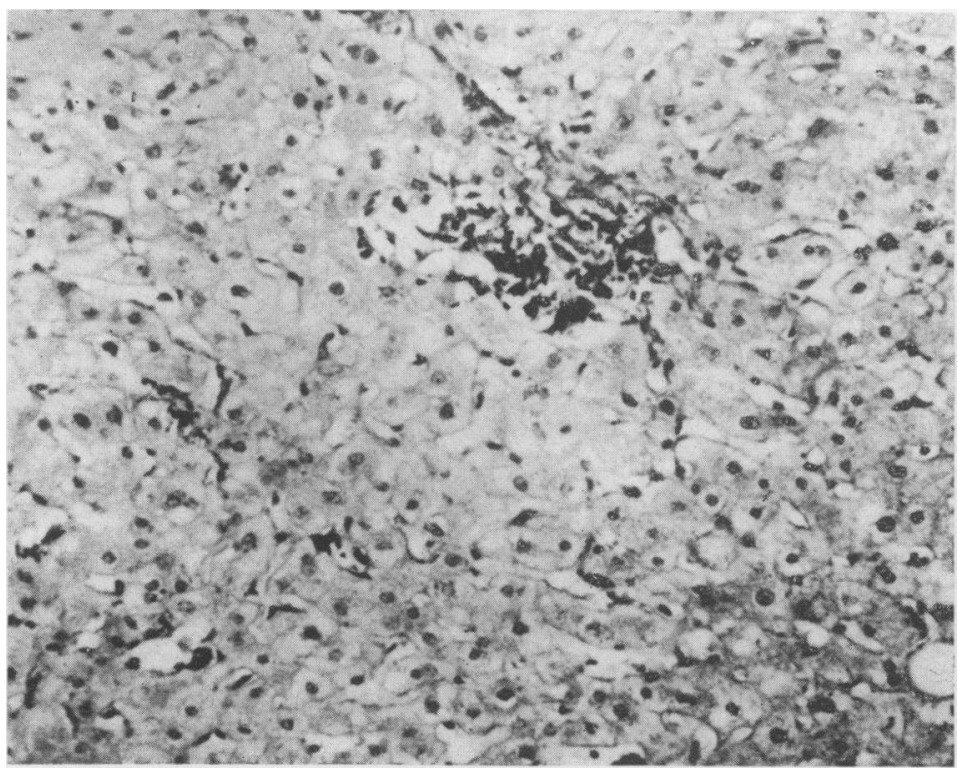

Frg. 1. Liver biopsy showing Kuppfer cells and portal tract phagocytes with intensely PAS-positive pigment (MC. Manus, $\times 130$ ).

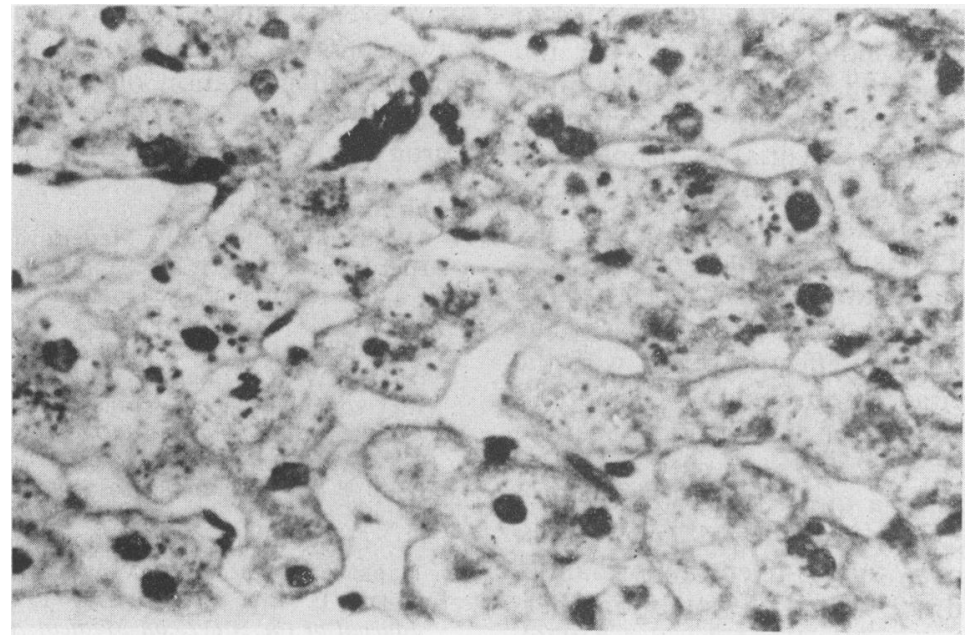

FIG. 2. Liver biopsy showing mild steatosis $(\mathrm{HE}, \times 250)$.

and alkaline phosphatase, 7.0 Bodansky units. Ten days later jaundice had resolved.

\section{Discussion}

One month after starting naproxen the patient developed jaundice which resolved after stopping the drug. There were no epidemiological data in favour of viral hepatitis $A$ and $\mathbf{H B}_{\mathbf{s}}$ antigen was negative. Lack of alcohol consumption preceding the episode and the histological appearances excluded alcoholic hepatitis. In fact, the liver biopsy findings were those of a resolving acute hepatitis-type lesion. The presence of eosinophilic infiltration and steatosis, which is not usual in viral hepatitis, in 


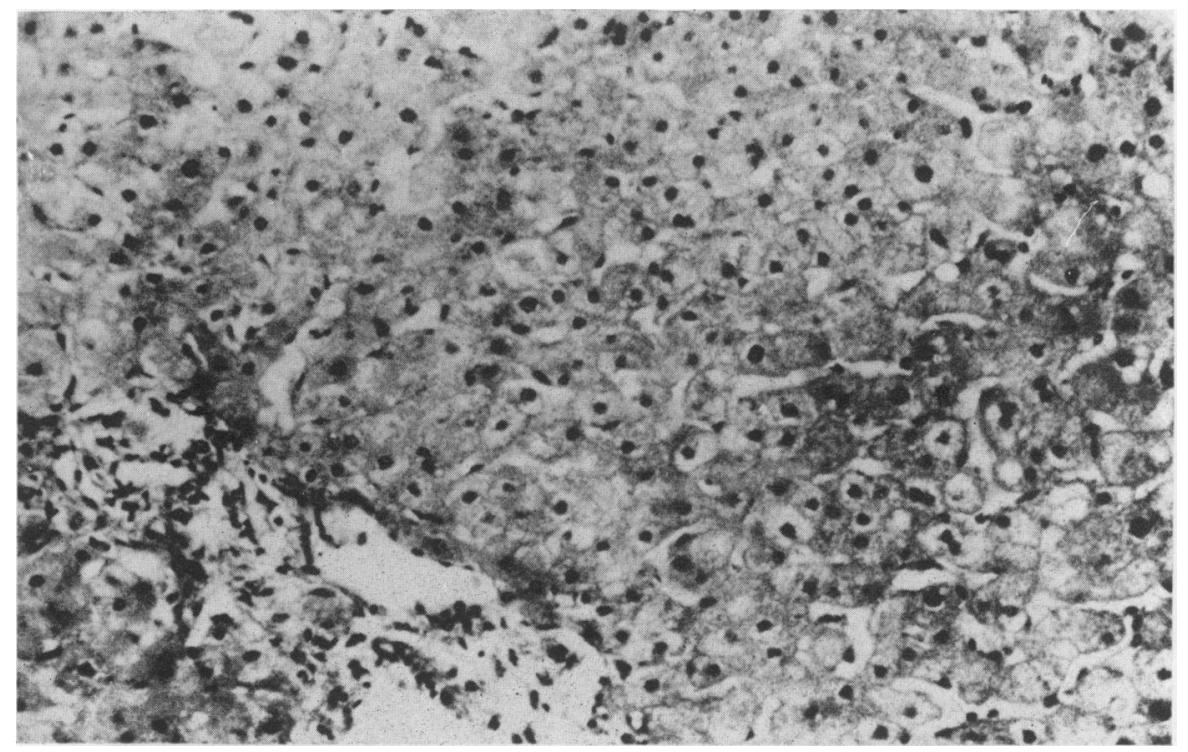

FIG. 3. Liver biopsy showing portal tract enlargement with oedema and cellular infiltration including some eosinophils $(\mathrm{HE}, \times 150)$.

conjunction with the temporal sequence and the exclusion of the above mentioned aetiologies led to the diagnosis of a drug-induced hepatitis. The use of a challenge test was not done in view of the initial severity of the clinical picture, together with the fact that naproxen was not essential to this patient's management. Finally, the clinical picture was in several aspects similar to the 2 previously reported cases (Bass, 1974; Law and Knight, 1976).

The presence of a relatively fixed sensitization period (one to 6 weeks) in the 3 reported cases, the apparent rarity of this side effect, together with the sudden onset of fever and the presence of eosinophils in the infiltrate in this case, are all circumstantial evidence supporting a hypersensitivity response to the drug rather than a direct hepatotoxic effect. Also the recent report of accidental ingestion of $25 \mathrm{~g}$ of naproxen without liver abnormalities (Fredell and Strand, 1977) and the study on pharmacokinetics of naproxen by Runkel, et al. (1976), provide further evidence against direct hepatotoxicity.
Thus, naproxen-associated jaundice is probabg rare event limited to sensitive individuals. Increased awareness by clinicians of this side effect may lo prompt identification of similar cases and preven continuing liver damage by early withdrawal of the drug.

\section{Acknowledgments}

We thank Professor F. Madeira, former Director of oů Department and Dr H. J. F. Hodgson, Senior Lecturer, Royâ Postgraduate Medical School, for their helpful comments

\section{References}

Frenger, W. \& Norbach, H.J. (1973) Klinische untersuch ung von Naproxen vor allen mit bezug auf seine Vertaglichkeit. Scandinavian Journal of Rheumatology, 2 (suppl. 137.

BASs, B.H. (1974) Jaundice associated with naproxen. Lance i, 998.

LAW, I.P. \& KNIGHT, H. (1976) Jaundice associated with Naproxen. New England Journal of Medicine, 295, 1201 J

Fredell, E.W. \& STrand, L.J. (1977) Naproxen overdosed Journal of the American Medical Association, 238, 938.

Runkel, R., Chaplin, M.D., Sevelius, H., Ortega, E. SEGRE, E. (1976) Pharmacokinetics of naproxen overdosem Clinical Pharmacology and Therapeutics, 20, 269. 